\title{
Determination of diclofenac concentrations in human plasma using a sensitive gas chromatography mass spectrometry method
}

\author{
Iltaf Shah ${ }^{2^{*}}$ (D, James Barker ${ }^{1}$, Declan P. Naughton', Stephen J. Barton ${ }^{1}$ and Syed Salman Ashraf ${ }^{2}$
}

\begin{abstract}
Background: A gas chromatography mass spectrometry (GCMS) method for the determination of diclofenac in human plasma has been developed and validated.

Results: This method utilizes hexane which is a relatively less toxic extraction solvent compared to heptane and benzene. In addition, phosphoric acid and acetone were added to the samples as deproteination agents, which increased the recovery of diclofenac. These revised processes allow clean extraction and near-quantitative recovery of analyte (approx. 89-95 \%). Separation was achieved on a BP-1 column with helium as carrier gas. The molecular ion peaks of the indolinone derivatives of diclofenac ion ( $\mathrm{m} / \mathrm{z} 277)$ and the internal standard, 4-hydroxydiclofenac ion ( $\mathrm{m} / \mathrm{z}$ 439) were monitored by a mass-selective detector using selected ion monitoring (SIM) mode. The linear range for the newly developed and highly sensitive assay was between $0.25-50 \mathrm{ng} / \mathrm{mL}$. The detection and lower quantifiable limits were 0.125 and $0.25 \mathrm{ng} / \mathrm{mL}$, respectively. The inter-day and intra-day coefficients of variation for high, medium and low quality control concentrations were less than $9 \%$. The robustness and efficacy of this sensitive GCMS method was further demonstrated by using it for a pharmacokinetic study of an oral dosage form of diclofenac, $100 \mathrm{mg}$ of modified-release capsules (Rhumalgan XL), in human plasma.
\end{abstract}

Conclusions: This method is rapid, sensitive, specific, reproducible and robust, and offers improved sensitivity over previous methods. This method has considerable potential to be used for detailed pharmacokinetics, pharmacodynamics and bioequivalence studies of diclofenac in humans.

Keywords: Human plasma, Diclofenac sodium, GCMS, Sensitive GCMS

\section{Background}

Sodium 2-(2,6-dichlorophenyl-aminophenyl acetate (diclofenac) salt is a nonsteroidal anti-inflammatory drug. Clinically, it is mostly used for the treatment of pain caused by inflammation [1-6]. In humans, "the absorption, distribution, metabolism, and excretion" (ADME) studies of diclofenac show that it has high inter- and intrasubject variability [7-17] that may arise from pharmacogenomics differences amongst individuals and/or precision

\footnotetext{
*Correspondence: altafshah@uaeu.ac.ae

${ }^{2}$ Department of Chemistry, College of Science, United Arab Emirates University, Al Ain, UAE

Full list of author information is available at the end of the article
}

in measurement procedures. Furthermore, due to wide availability of diclofenac formulations, there is an interest in having robust and sensitive assays for diclofenac quantitation for pharmacokinetics studies. This could be especially important in developing countries with nascent pharmaceutical industries, who may synthesize and sell their own diclofenac formulations. To start this inquest, we have developed a gas chromatographic mass spectrometric (GCMS) method for the detection and quantification of diclofenac concentrations in human plasma. Many methods have been developed for the determination of diclofenac in biological specimens e.g. high pressure liquid chromatography with ultra violet detection (HPLC-UV) 
[18-21], HPLC with electrochemical detection [22, 23] and online micro-dialysis with liquid chromatography [24], electro-membrane extraction (EME) and pulsedelectro-membrane extraction (PEME) coupled with HPLC [25], liquid chromatography mass spectrometry (LCMS) $[26,27]$ and GCMS methods [28-31].

While GCMS methods have been the favorite choice in the past, many derivatisation reagents have been tried and tested. Borenstein et al. used pentafluoropropionic anhydride (PFPA) as a derivatising agent with lower limit of quantification (LOQ) of $1 \mathrm{ng} / \mathrm{mL}$ with a $95 \%$ recovery [30]. Choi et al. used a mixture of PFPA and a mixture (1000:2:3,v/w/w) of $N$-methyl- $N$-trimethylsilyltrifluoroacetamide (MSTFA), ammonium iodide $\left(\mathrm{NH}_{4} \mathrm{I}\right)$, and dithioerythritol (DTE) as derivatisation reagent. With this method the LOQ was $0.5 \mathrm{ng} / \mathrm{mL}$ and the recovery approximately $97 \%$ [32]. Yilmaz et al. described a method where MSTFA was used as the derivatising agent (silylating reagent), and the hydroxyl group of diclofenac was O-silylated. Here the LOQ was $5 \mathrm{ng} / \mathrm{mL}$ with a recovery of about $96 \%$ [31]. In our work PFPA was chosen as the best derivatising agent due to it giving a better sensitivity and maximum recovery.

HPLC-UV methods have been reported to measure plasma diclofenac in the range ca. $10-100 \mathrm{ng} / \mathrm{mL}$ [18-20]. Plasma matrix and other diclofenac metabolites are also known to cause interferences in accurate diclofenac estimation in human matrices [29]. To ensure good specificity and reproducibility, lengthy and comprehensive sample preparation procedures are often required [16-18]. On the other hand, mass spectrometric methods offer potentially better precision, accuracy, sensitivity and recovery, with a detection limit of between $0.2-2 \mathrm{ng} / \mathrm{mL}[26,27,30,33]$. The reported mass spectrometric methods used benzene and heptane as extraction solvents. However, the sensitivity of these methods was not good enough to carry out a thorough and accurate lower dose pharmacokinetic analysis of diclofenac in human plasma. In the present study, we have modified existing methods [29-31] introducing hexane, acetone and sodium bicarbonate to develop a more sensitive, specific and reproducible method for the determination of diclofenac in human plasma.

Having developed and validated a method for the quantification of diclofenac in plasma we sought to demonstrate a proof-of-concept application. For this purpose, plasma samples were obtained from 30 volunteers who had been given an oral dosage of $100 \mathrm{mg}$ of diclofenac sodium (Rhumalgan XL $100 \mathrm{mg}$ modified-release capsules). Human plasma samples were analysed between 0 and $12 \mathrm{~h}$ to evaluate the pharmacokinetic parameters of diclofenac.

\section{Methods}

\section{Chemicals and reagents}

Diclofenac sodium salt (analytical standard), 4-hydroxydichlofenac ( $>98 \%$ pure), concentrated phosphoric acid solution of $85 \%(\mathrm{w} / \mathrm{v})$, derivatising agent PFPA (99\% pure) and sodium hydrogen carbonate ( $>99.7 \%$ pure) were purchased from Sigma-Aldrich Ltd Dorset, UK. Methanol $(\mathrm{MeOH})$, acetone, chloroform, water and hexane of HPLC grade were purchased from Hichrom Ltd, Reading, Berks, UK. Drug free human plasma was obtained from TCS Biosciences Ltd, Buckingham, UK.

\section{Apparatus and assay conditions}

GCMS was performed with a Hewlett Packard model 6890 Gas Chromatograph (GC) fitted with a 6890 autoinjector for a pulsed splitless injection coupled to a model 5973 Mass Selective Detector (MSD) (Agilent Technologies, USA). Separation was achieved using a BP-1 fused silica capillary column $(15 \mathrm{~m} \times 250 \mu \mathrm{m} \times 0.25 \mu \mathrm{m})$. Helium ( $99.95 \%$, BOC Gases, Surrey, UK) was used as a carrier gas at a flow-rate of $1.2 \mathrm{~mL} / \mathrm{min}$. The injection volume was $2 \mu \mathrm{L}$. The syringe size was $10 \mu \mathrm{L}$. Pulse pressure and pulse time were $20 \mathrm{psi}$ and $0.5 \mathrm{~min}$ respectively. Total run time was $14.5 \mathrm{~min}$. Injector temperature was $280{ }^{\circ} \mathrm{C}$. The initial oven temperature was $150{ }^{\circ} \mathrm{C}$, whilst the final oven temperature was $300{ }^{\circ} \mathrm{C}$. The final high temperature purged residual materials from the column. The column temperature was initially held at $150{ }^{\circ} \mathrm{C}$ for $4 \mathrm{~min}$ (total run time $4 \mathrm{~min}$ ), increased at $4{ }^{\circ} \mathrm{C} / \mathrm{min}$ to $180{ }^{\circ} \mathrm{C}$ in $7.5 \mathrm{~min}$ and held there for $0.5 \mathrm{~min}$ (run time $12 \mathrm{~min}$ ), then increased at $60{ }^{\circ} \mathrm{C} / \mathrm{min}$ to $300{ }^{\circ} \mathrm{C}$ in $2 \mathrm{~min}$ and held there for $0.5 \mathrm{~min}$ (run time $14.5 \mathrm{~min}$ ). Carrier gas flowrate at the split vent was $54.3 \mathrm{~mL} / \mathrm{min}$. The injector was set to auto clean itself by pre-injecting hexane.

The mass selective detector was operated in the selected ion monitoring mode (with electron impact) and set at $\mathrm{m} / \mathrm{z}\left[\mathrm{M}^{+}\right] 214,242$ and 277 and $\mathrm{m} / \mathrm{z} 376$ and 439 for the detection of diclofenac and 4-hydroxydiclofenac, respectively. The corresponding retention times of diclofenac and 4-hydroxydiclofenac were $7.5 \mathrm{~min}$ and $8.5 \mathrm{~min}$ respectively (for a $100 \mathrm{~ms}$ dwell). The relative retention times of diclofenac to 4-hydroxydiclofenac was 1.13 with a standard deviation of 0.01 . Solvent delay was $3 \mathrm{~min}$, electron multiplier accelerating voltage $2494 \mathrm{~V}$ and electron ionisation energy $70 \mathrm{eV}$. Mass spectrometer source, quadrupole and transfer line temperatures were 230,150 and $280{ }^{\circ} \mathrm{C}$, respectively. The accelerating voltage was set at $3.5 \mathrm{kV}$. The system was controlled and detector output data was processed using a Chemstation version B.00.02 software. 


\section{Preparation of standards}

A stock solution of $1 \mathrm{mg} / \mathrm{mL}$ was prepared by adding $10.78 \mathrm{mg}$ of Diclofenac in $10 \mathrm{~mL}(\mathrm{MeOH})$ (Final conc. $1.078 \mathrm{mg} / \mathrm{mL}$ ). Working solutions were prepared by serial dilutions of the stock solution. A $0.45 \mathrm{mg} / \mathrm{mL}$ stock solution of 4-hydroxydiclofenac was prepared by dissolving $4.5 \mathrm{mg}$ of 4-hydroxydiclofenac in $10 \mathrm{~mL} \mathrm{MeOH}$. The concentration of the working internal standard solution of 4-hydroxydiclofenac was $0.0045 \mathrm{mg} / \mathrm{mL}$. All solutions were stored at $-20{ }^{\circ} \mathrm{C}$.

\section{Preparation of $1 M$ phosphoric acid}

$33.3 \mathrm{~mL}$ of concentrated phosphoric acid solution of $85 \%$ $(\mathrm{w} / \mathrm{v})$ strength was diluted with $500 \mathrm{~mL}$ deionised water to give a solution of $1 \mathrm{M}$ concentration. The bottle was labelled and an expiry date of 2 months from the date of preparation was applied. The solutions were found to be stable for this duration. The solution was stored at room temperature.

\section{Preparation of $0.08 \mathrm{M}$ sodium hydrogen-carbonate solution}

Approximately $0.672 \mathrm{~g}$ of sodium hydrogen carbonate was weighed and diluted with $100 \mathrm{~mL}$ of HPLC grade water, stored at room temperature with an expiry date of 2 months.

\section{Sample preparation}

Appropriately labelled Pyrex glass tubes $(100 \times 13 \mathrm{~mm})$ with screw caps were used. Plasma samples $(1 \mathrm{~mL})$ were added to the sample tubes. An internal standard of 4-hydroxydiclofenac $(25 \mu \mathrm{L})$ of concentration $0.0045 \mathrm{mg} / \mathrm{mL}$ was added and the mixtures acidified and vortex mixed with1 $\mathrm{M}$ phosphoric acid $(1 \mathrm{~mL})$. Then, to all tubes, $1 \mathrm{~mL}$ of acetone was added for deproteination followed by vortex mixing. Next, $5 \mathrm{~mL}$ of $\mathrm{n}$-hexane was added, the tubes capped and the samples placed on a roller mixer for $15 \mathrm{~min}$. All the tubes were centrifuged at $1400 \times g$ for $5 \mathrm{~min}$ at room temperature. The top hexane layer was transferred to glass screw-capped tubes to which $1 \mathrm{~mL}$ of $0.08 \mathrm{M}$ sodium hydrogen carbonate solution was added for basification and to increase partition of the drug into the aqueous layer. The tubes were capped and again placed on a roller mixer for $15 \mathrm{~min}$ and centrifuged at $3000 \times g$ for $5 \mathrm{~min}$. The upper hexane layer was aspirated and discarded. Phosphoric acid $(1 \mathrm{~mL})$ was then added, followed by $5 \mathrm{~mL}$ of $\mathrm{n}$-hexane. The tubes were then placed on a roller mixture for a further $15 \mathrm{~min}$ and centrifuged for $5 \mathrm{~min}$ at $3000 \times g$ and the top hexane layer was transferred to glass tubes $(100 \times 13 \mathrm{~mm}$, without screw cap). Hexane was then evaporated off under a stream of nitrogen with the heater block set at $35^{\circ} \mathrm{C}$.

\section{Derivitisation of the samples}

n-Hexane $(975 \mu \mathrm{L})$ and $25 \mu \mathrm{L}(\mathrm{v} / \mathrm{v})$ of PFPA were added to the dried residue and the tubes vortex mixed for $30 \mathrm{~s}$. The samples were allowed to react for $30 \mathrm{~min}$ on a heater block at $35{ }^{\circ} \mathrm{C}$ and gently evaporated under a stream of nitrogen. The tubes were allowed to cool to room temperature and the derivatised compound was reconstituted into $80 \mu \mathrm{L}$ of chloroform. The sample was transferred to autosampler vials and the GCMS autosampler programmed to inject $2 \mu \mathrm{L}$ of the sample. Figure 1 shows the indolinone derivatives formed from derivatisation of diclofenac sodium and 4-hydroxydiclofenac using the derivatising agent PFPA.

This newly developed analytical method was tested in a human pharmacokinetic study. Plasma samples obtained after administration of $100 \mathrm{mg}$ of oral diclofenac sodium in participating volunteers were analysed to quantitate the plasma concentrations of the drug over a $12 \mathrm{~h}$ period. Kingston University research ethics committee approved the protocol and the volunteers provided informed written consent to participate.

\section{Validation \\ Calibration curve and analysis}

The working standard solutions for plasma analysis were made by serial dilution of the stock solutions to final concentrations of 10, 20, 40, 200, 400, 1000 and $2000 \mathrm{ng} / \mathrm{mL}$ in methanol. Calibration standards were obtained by spiking $25 \mu \mathrm{L}$ of each of these standards into $975 \mu \mathrm{L}$ of human plasma to produce concentrations of $0.25,0.5,1,5,10,25$ and $50 \mathrm{ng} / \mathrm{mL}$. The samples for the standard curve were processed as described in the materials and method section. The ratio of peak area of diclofenac to that of the internal standard was plotted versus the concentration of the diclofenac in the calibration standard and a leastsquares linear regression analysis was performed. Values of unknown plasma concentrations were determined from the regression line of this calibration curve. The working quality control solutions in methanol for plasma analysis were made by serial dilution of the stock solutions to obtain final concentrations of 10, 20, 44, 600 and $1600 \mathrm{ng} /$ $\mathrm{mL}$. Quality controls were obtained by spiking $25 \mu \mathrm{L}$ of each of these standards into $975 \mu \mathrm{L}$ of human plasma to produce concentrations of $0.25,0.5,1.1,15$ and $40 \mathrm{ng} / \mathrm{mL}$. All methanolic solutions were stored at $2-8{ }^{\circ} \mathrm{C}$ with an expiry of 7 days, due to their short stability in methanol, while plasma samples were stored at $-20^{\circ} \mathrm{C}$.

\section{Intra-inter day precision and accuracy}

The accuracy and precision of the method was determined by assaying $0.5 \mathrm{~mL}$ aliquots of ethylene-diaminetetra-acetic acid (EDTA) human plasma fortified with 


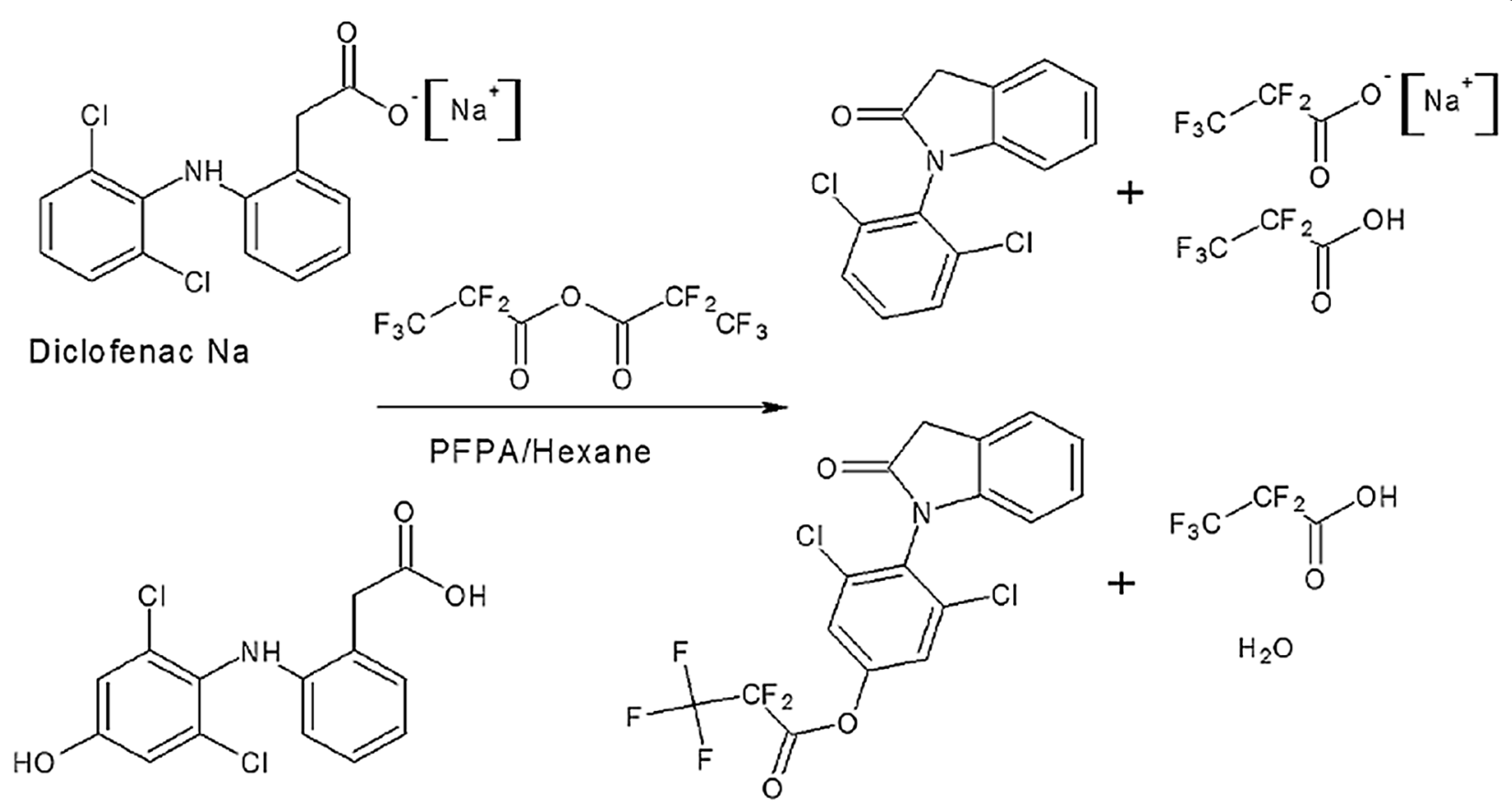

Fig. 1 Formation of indolinone derivatives for both diclofenac-Na and 4-hydroxydiclofenac in the presence of derivatising agent PFPA

four quality control (QC) samples of 0.5, 1.1, 15.0 and $40.0 \mathrm{ng} / \mathrm{mL}$ of diclofenac. These fortified samples were later assayed by GCMS. To assess the inter-assay precision and accuracy, samples were analysed on five separate days. To assess the intra-assay precision, these same QC concentrations were analysed and compared during 1 day.

\section{Linearity, sensitivity and specificity}

The ratio of diclofenac and 4-hydroxydiclofenac responses were plotted by GCMS ChemStation Version 3.1 software to determine the linearity. A calibration point was rejected as an outlier if the back-calculated concentration for a calibrator (on the basis of the corresponding calibration curve) deviated by more than $15 \%$ at all concentrations covered by the calibration range, except at the lower limit of quantitation (LLOQ), where a deviation of $20 \%$ was acceptable. A calibration curve was allowed with a minimum of four acceptable calibration levels. These criteria were based on the US Food and Drug Administration (FDA) "Bioanalytical Method Validation: Guidance for Industry" protocol [34].

The analytical method was able to determine diclofenac and 4-hydroxydiclofenac (internal standard) in plasma without significant interference from other endogenous compounds. The specificity of the validated assay procedure was shown by analysing 6 blank plasma samples from subjects not exposed to diclofenac, it was then spiked and recoveries calculated.

\section{Extraction recovery}

Absolute extraction recovery of diclofenac from human EDTA plasma was determined at three concentration levels: $1.1,15$ and $40 \mathrm{ng} / \mathrm{mL}$. The area ratio response of diclofenac to internal standard in the extracted sample divided by the area ratio response determined in an unextracted sample and multiplied by 100 gave the percent recovery. These samples were extracted, as described earlier, except that the internal standard was added to the collected extract. The concentrations of the spiked plasma samples were calculated from the curve and compared to the theoretical values in order to calculate the extraction recovery.

\section{Stability}

The stability of diclofenac in human EDTA plasma was determined in processed sample extracts over at least $24 \mathrm{~h}$ period and also by three repeated freezing and thawing cycles. 
Stability of diclofenac in EDTA plasma to repeated freezing and thawing cycles

Human EDTA plasma samples at concentration of $\mathrm{QCL}=1.1 \mathrm{ng} / \mathrm{mL}, \mathrm{QCM}=15 \mathrm{ng} / \mathrm{mL}$ and $\mathrm{QCH}=40 \mathrm{ng} /$ $\mathrm{mL}$ were subjected to three freezing and thawing cycles. The time span for freeze/thaw cycles was $72 \mathrm{~h}$ with each freeze/thaw cycle lasting for $24 \mathrm{~h}$ with time points 24,48 and $72 \mathrm{~h}$. The results obtained after each freezing and thawing cycle were expressed as a percentage change from the results for QCL $=1.1 \mathrm{ng} / \mathrm{mL}, \mathrm{QCM}=15 \mathrm{ng} /$ $\mathrm{mL}$ and $\mathrm{QCH}=40 \mathrm{ng} / \mathrm{mL}$ in the intra-assay run (validation run-1, these samples were prepared fresh and had not experienced any freezing conditions). The test compound was considered to be stable if the percentage change from freshly prepared samples was within $\pm 15 \%$ of the nominally spiked level.

\section{Pharmacokinetics study}

The pharmacokinetic study chosen, set out to analyze diclofenac sodium in human plasma. For this study, plasma samples were obtained from 30 volunteers who had been given an oral dosage of $100 \mathrm{mg}$ of diclofenac sodium (Rhumalgan $\mathrm{XL}^{\mathrm{TM}} 100 \mathrm{mg}$ modified-release capsules). Diclofenac concentrations in plasma were measured between 0 and $12 \mathrm{~h}$, (blood being collected every hour) in order to evaluate the pharmacokinetic parameters of diclofenac. Kingston University Faculty of Science Research Ethics Committee approved the protocol and the volunteers provided informed written consent to participate. The pharmacokinetic study was conducted according to the principles of the Declaration of Helsinki [35]. According to FDA guidelines for generic drugs studies, the area under the curve (AUC) was calculated using a linear trapezoidal method, by applying non-compartmental data analysis. The method developed was used to investigate the plasma profile after oral dosing of diclofenac sodium $100 \mathrm{mg}$ capsules in 30 healthy young male volunteers.

\section{Results and discussion}

Diclofenac sodium and 4-hydroxydiclofenac react with the derivatising agent PFPA to form indolinone derivatives, which upon electron ionisation gave rise to diclofenac ions at $\mathrm{m} / \mathrm{z} 277,242$ and 214, whilst 4-hydroxydiclofenac gave ions at $\mathrm{m} / \mathrm{z} 439$ and 376.

\section{Calibration curve and analysis}

Figure 2 displays a representative chromatogram of blank plasma spiked with $0.25 \mathrm{ng} / \mathrm{mL}$ of diclofenac and $0.0045 \mathrm{ng} / \mathrm{mL}$ of the internal standard. Pooled normal human plasma yielded relatively clean chromatograms with no significant interfering peaks. Both diclofenac and the internal standard showed sharp, well-defined peaks at retention times of 7.5 and $8.5 \mathrm{~min}$, respectively.
The mass spectra of diclofenac and the internal standard are shown in Fig. 3a, b. The derivatised indolinone ions for diclofenac and its internal standard fragment differently in the mass spectrometer giving rise to two distinctly different indolinone ions as shown in Fig. 3a, b.

\section{Linearity, sensitivity and specificity}

During the validation study, calibration curves were generated over a diclofenac concentration range of $0.25-50 \mathrm{ng} / \mathrm{mL}$. The method showed good sensitivity, specificity and linearity in the concentration range $0.25-$ $50 \mathrm{ng} / \mathrm{mL}$. The plots were linear over the concentration range $0.25-50 \mathrm{ng} / \mathrm{mL}$.

The curves were all linear with a mean coefficient of determination of 0.9996 , see Table 2 . To evaluate the curve, the observed responses for the individual standards were substituted back into the equation in order to calculate the predicted concentrations based on the calibration curve. The limit of quantitation was $0.25 \mathrm{ng} / \mathrm{mL}$. Using a signal-to noise ratio measure, the estimated limit of detection was $0.125 \mathrm{ng} / \mathrm{mL}$.

Furthermore, as can be seen from the Table 1, the percentage recovery of diclofenac in spiked plasma samples, was well within the accepted limit of 85-115\%, thereby showing no matrix effects. No notable peaks were seen in the region of interest when six blank plasma samples were analyzed, see Table 1 . The retention time region of the chromatograph where diclofenac and 4-hydroxydiclofenac eluted was clear in these samples and demonstrated the specificity of the validated analytical procedure. No interference from endogenous compounds or metabolites of diclofenac was found around the elution times, however a matrix peak was observed at a different retention time see Fig. 4.

\section{Intra and Inter assay accuracy and precision}

The inter-assay accuracy and precision were calculated from results obtained from quality control samples $(\mathrm{N}=6)$ analysed at four concentrations $(0.5,1.1,15$ and $40 \mathrm{ng} / \mathrm{mL}$ of diclofenac in EDTA plasma representing LLOQ, QCL, QCM and QCH respectively) on three separate occasions, see Table 2.

\section{Recovery}

Our initial attempts gave a respectable recovery of the spiked drug at ca. $60 \%$. However, further experiments using acetone and sodium bicarbonate showed that the simple addition of these two reagents resulted in a dramatic increase in recovery by $50 \%$. Final recoveries were calculated during validation runs as shown in Table 2.

Intra and inter day precision (coefficient of variation) ranged between 2.41-6.33 and 7.51-8.87 \% respectively, while intra and inter day accuracy ranged between 


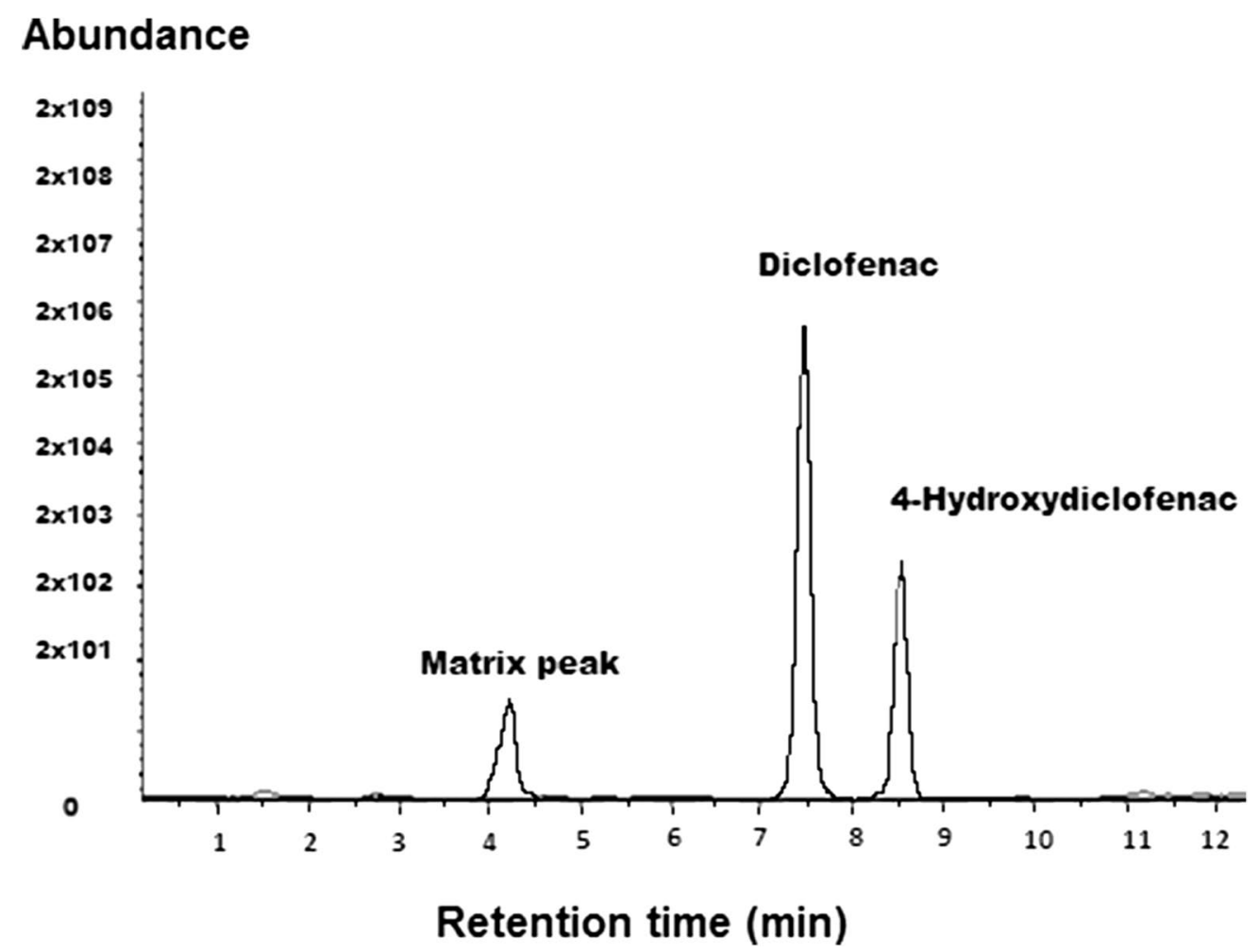

Fig. 2 Chromatographs of diclofenac $(0.25 \mathrm{ng} / \mathrm{mL})$ and 4-hydroxydiclofenac $(0.0045 \mathrm{ng} / \mathrm{mL})$ derivatives in plasma

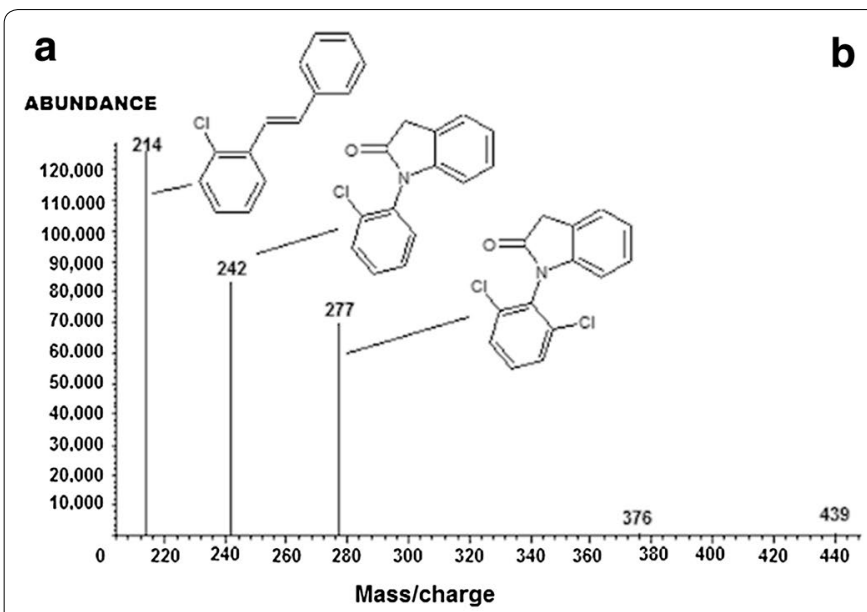

b

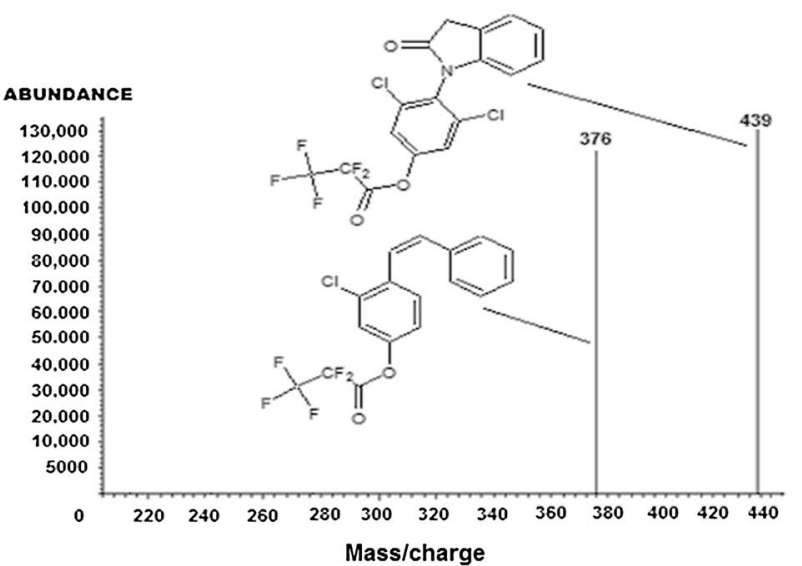

Fig. 3 a Mass spectrum showing abundant ions for diclofenac derivative. b Mass spectrum showing abundant ions of 4-hydroxydiclofenac derivative

Table 1 Recovery of diclofenac standards when added to blank plasma showing no notable matrix effect $(n=6)$

\begin{tabular}{lc}
\hline $\begin{array}{l}\text { Nominal concentration } \\
(\mathbf{n g} / \mathbf{m L})\end{array}$ & $\begin{array}{l}\text { Recovery } \\
\text { Mean } \pm \text { SD (\%) }\end{array}$ \\
\hline 0.5 & $97.45 \pm 6.21$ \\
1.1 & $98.63 \pm 5.22$ \\
15 & $100.52 \pm 4.73$ \\
40 & $97.59 \pm 7.21$ \\
\hline
\end{tabular}

88.98-95.82 and 95.73-102.01\% respectively. The percent recovery of the three QC's ranged between 89.86$94.76 \%$, see Table 2 .

\section{Freezing and thawing cycles}

The $\mathrm{QCL}=1.1 \mathrm{ng} / \mathrm{mL}$ samples gave a mean result of $1.96,2.02$ and $1.88 \mathrm{ng} / \mathrm{mL}(\mathrm{n}=6)$ with the corresponding percentage change from freshly prepared samples of $+9.49,+12.93$ and $+4.83 \%$ for 


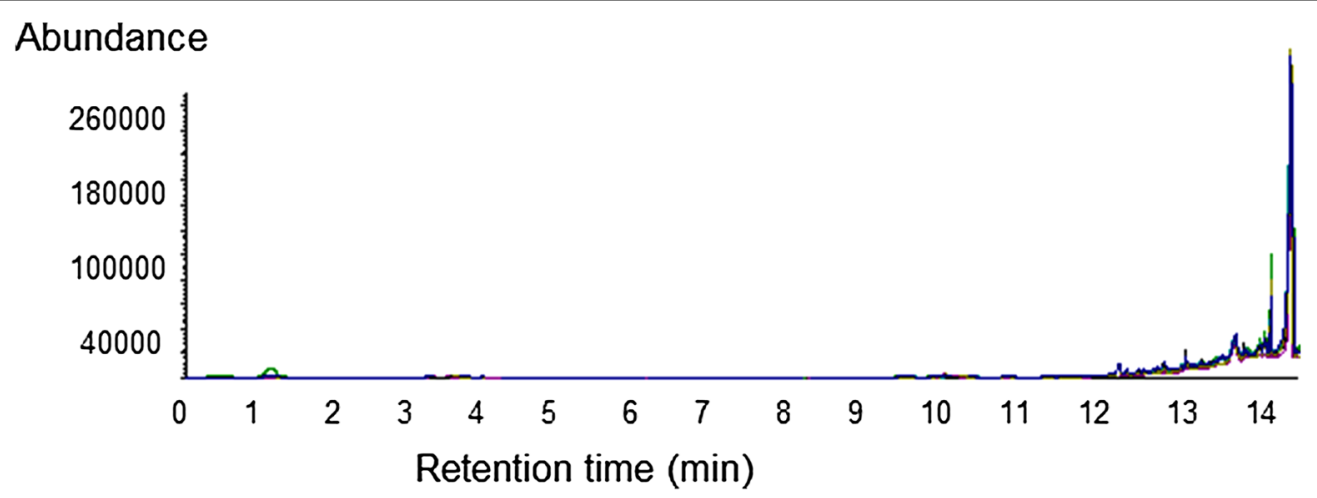

Fig. 4 Overlay chromatograms of six blank plasma samples showing specificity

Table 2 Summary of assay validation results including precision and accuracy data

\begin{tabular}{|c|c|c|c|c|c|c|c|c|c|}
\hline \multirow{2}{*}{$\begin{array}{l}\text { Analyte } \\
\text { (ng/mL) }\end{array}$} & \multirow{2}{*}{$\begin{array}{l}\mathrm{QC} \\
\text { (ng/ } \\
\mathrm{mL})\end{array}$} & \multirow{2}{*}{$\begin{array}{l}\text { Linear range } \\
(\mathrm{ng} / \mathrm{mL})\end{array}$} & \multirow{2}{*}{$\begin{array}{l}\text { LOD } \\
\text { (ng/ } \\
\mathrm{mL})\end{array}$} & \multirow[t]{2}{*}{$r^{2}$} & \multicolumn{2}{|l|}{ Intra-day $(\mathrm{N}=6)$} & \multicolumn{2}{|l|}{ Inter-day $(\mathrm{N}=6)$} & \multirow[t]{2}{*}{ Recovery \% } \\
\hline & & & & & Precision $\% \mathrm{CV}$ & Accuracy \% & Precision, $\% \mathrm{CV}$ & Accuracy $\%$ & \\
\hline \multirow[t]{4}{*}{ Diclofenac $\mathrm{Na}$} & 0.5 & $0.25-50$ & 0.125 & 0.9996 & 6.33 & 95.82 & 8.64 & 102.01 & \\
\hline & 1.1 & & & & 2.41 & 89.45 & 8.87 & 99.54 & 94.76 \\
\hline & 15 & & & & 5.39 & 91.12 & 7.70 & 99.47 & 91.77 \\
\hline & 40 & & & & 3.41 & 88.98 & 7.51 & 95.73 & 89.86 \\
\hline
\end{tabular}

$L O D$ limit of detection, \% CV coefficient of variation

freezing and thawing cycles 1,2 and 3 respectively. The $\mathrm{QCM}=15 \mathrm{ng} / \mathrm{mL}$ samples gave a mean result of $18.85,18.97$ and $19.19 \mathrm{ng} / \mathrm{mL}(\mathrm{n}=6)$ with the corresponding percentage change from freshly prepared samples of +3.42 , +4.11 and $+5.29 \%$ for freezing and thawing cycles 1,2 and 3 respectively. The $\mathrm{QCH}=40 \mathrm{ng} / \mathrm{mL}$ samples gave a mean result of 51.05 , 51.23 and $50.85 \mathrm{ng} / \mathrm{mL}(\mathrm{n}=6)$ with the corresponding percentage change from freshly prepared samples of $+4.32,+4.69$ and $+3.91 \%$ for freezing and thawing cycles 1,2 and 3 respectively. The data indicated that diclofenac was stable in EDTA plasma to at least three freezing and thawing cycles.

The validation results indicated that the proposed method is more efficient in detecting the non-steroidal anti-inflammatory drug diclofenac, in human plasma even at very low levels when only ca. $1000 \mu \mathrm{L}$ of human plasma was processed. Under the extraction and chromatographic conditions employed, there were no detectable interferences by endogenous materials present in human plasma.

Three freezing and thawing cycles showed that diclofenac was stable in EDTA plasma. The average percent variation from freshly prepared EDTA samples, at three concentration levels, were 9.1, 4.27 and $4.3 \%$ respectively.
Many GCMS derivatization reagents has been tried and tested in the past to get maximum sensitivity and ultimate recovery of diclofenac from human plasma. Choi et al. showed that when a mixture of PFPA and a mixture (1000:2:3, v/w/w) of $N$-methyl- $N$-trimethylsilyltrifluoroacetamide (MSTFA), ammonium iodide $\left(\mathrm{NH}_{4} \mathrm{I}\right)$, and dithioerythritol (DTE) were used as derivatisation reagents, the lower limit of quantification (LOQ) was $0.5 \mathrm{ng} / \mathrm{mL}$. While we have used PFPA as a derivatisation reagent, with an improved LOQ of $0.25 \mathrm{ng} / \mathrm{mL}$ and a similar recovery to Choi's work [32]. Yilmaz et al. described a method where MSTFA was used as derivatising agent (silylating reagent). Here, the LOQ was a factor of ten higher at $5 \mathrm{ng} / \mathrm{mL}$ with a recovery of about $96 \%$ [31]. Others who have used PFPA as a derivatising agent include Borenstein et al. who achieved a lower limit of quantification (LOQ) of $1 \mathrm{ng} / \mathrm{mL}$ with a $95 \%$ recovery and Kadowaki et al. who reported a LOD (LOQ not reported) of $0.2 \mathrm{ng} / \mathrm{mL}$ and recoveries of ca. $83 \%$. However, they used benzene as an extraction solvent which is more toxic [29]. Electro-membrane extraction (EME) and pulsed electro-membrane extraction (PEME) coupled with HPLC gave an LOD of $10 \mathrm{ng} / \mathrm{mL}$ an LOQ was not reported [25].

Our method has given a considerable improvement over the above methods with increased sensitivity LOQ 
$0.25 \mathrm{ng} / \mathrm{mL}$ and greater than $90 \%$ recovery. Hexane was used in the sample preparations steps instead of heptane and benzene, as it is a relatively less toxic extraction solvent. Furthermore, use of hexane resulted in a higher recovery of $>90 \%$ as compared to the published lower recoveries (around $83 \%$ ) for heptane and benzene [16-20].

In short the developed and validated GCMS method for diclofenac satisfy all the criteria for US-FDA's "Guidance for Industry Bioanalytical Method Validation:" [34] The method is very reliable and robust for quantitative determination of diclofenac in human plasma.

\section{Assay application}

The pharmacokinetic study was conducted and applied to 30 volunteers who had been given an oral dosage of $100 \mathrm{mg}$ of diclofenac sodium (Rhumalgan XL $100 \mathrm{mg}$ modified-release capsules). The amount of diclofenac was determined between 0 and $12 \mathrm{~h}$ in human plasma. The mean plasma concentration-time curve is shown in Fig. 5.

Diclofenac sodium is rapidly absorbed from the gut and undergoes first-pass metabolism [17, 36]. Rhumalgan $\mathrm{XL} 100^{\mathrm{TM}}$ capsules give the peak plasma concentrations $\left(\mathrm{C}_{\max }\right)$ at approximately $2.1 \mathrm{~h}\left(\mathrm{~T}_{\max }\right)$, where $\mathrm{T}_{\max }$ is the maximum time at which $\mathrm{C}_{\max }$ was observed after administration. The total drug exposure, which is the area under the curve (AUC) over time was calculated from the concentration time data.

According to FDA guidelines, for generic drugs studies, the area under the curve (AUC) was calculated by the Linear Trapezoidal method, by applying,

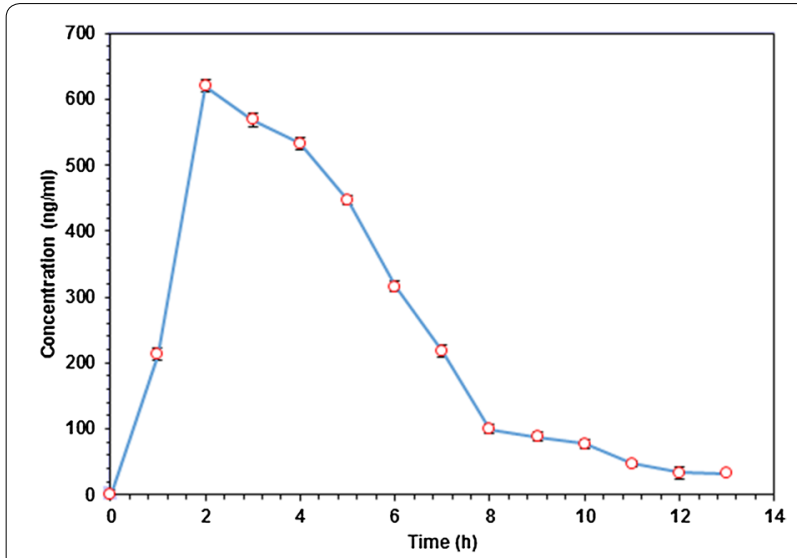

Fig. 5 Plasma concentration-time profiles of Diclofenac following a single oral dose of $100 \mathrm{mg}$ of modified release capsules (Rhumalgan $\mathrm{XL}$ ). The error bars represent the standard error of mean non-compartmental data analysis using the PK Solver 2.0 software (as an Excel add-on).

Here $\mathrm{AUC}_{0-\infty}$ is the extrapolated value of the AUC curve to infinite time and $\mathrm{AUC}_{0-12}$ is the AUC timeconcentration curve to the last measurable concentration at the $12 \mathrm{~h}$ time-point. The mean values of pharmacokinetic parameters estimated are shown in Table 3 [1-5]. Based on our new GCMS method, drug quality parameters like bioavailability and bioequivalence could be estimated accurately based on pharmacokinetic measures such as AUC and $C_{\max }$ that are reflective of systemic exposure. In humans, the pharmacokinetics of diclofenac retention and absorption show that it has high inter- and intra-subject variability [3, $5-7,9-16]$. In light of these previously reported interand intra- variability, our method (although assayed on a relatively small sample of 30 subjects) seems to be especially valuable as it showed very small variability and high reproducibility.

A possible reason for this reduction in inter- and intraindividual variability as compared to other methods may be the use of new extraction solvents such as hexane along with phosphoric acid, acetone and sodium bicarbonate for increased deproteination and PFPA as a robust and efficient derivatising agent.

The newly developed and validated method could have far reaching impact in pharmacokinetic and bioequivalence studies of diclofenac sodium in human patients. The proposed method might be applied to other human and animal matrices in future studies for accurate quantitation of diclofenac. This new method will also be instrumental in any future drug studies to show bioequivalence between generic and innovator drug products.

\section{Conclusions}

The developed and validated method for the determination of diclofenac in human plasma is rapid, sensitive, specific, reproducible and robust, and offers

Table 3 Pharmacokinetic parameters, where AUC shows area under curve and $C_{\max }$ shows the peak plasma concentration of the drug after administration, $T_{\max }$ shows time to reach $\mathrm{C}_{\max }$

\begin{tabular}{lcc}
\hline Parameter & Mean \pm SD & Confidence level (95 \%) \\
\hline$C_{\text {max }}(n g / m L)$ & $625 \pm 8.4$ & 13.4 \\
$T_{\max }(h)$ & $2.0 \pm 0.45$ & 0.72 \\
$A \cup C_{0-12}(\mathrm{ng} / \mathrm{mL} h)$ & $3243 \pm 9.8$ & 15.6 \\
$\mathrm{AUC}_{0-\infty}(\mathrm{ng} / \mathrm{mL})$ & $3331 \pm 8.3$ & 13.1 \\
\hline
\end{tabular}

SD standard deviation 
better sensitivity than previous methods. It utilizes hexane which is a relatively less toxic extraction solvent as compared to heptane and benzene, while phosphoric acid, acetone and sodium bicarbonate were used for increased deproteination. Due to the very small variability and high reproducibility this method has been proved to be suitable for use in pharmacokinetic studies of diclofenac in human plasma, which demonstrates the possible adequacy of this assay for clinical studies.

\section{Authors' contributions}

IS, JB, SJB and DPN initiated the study. All authors contributed to the study design, interpretation of the results and preparation of the manuscript. The method development, validation and sample analyses were conducted by IS with contributions from JB, SSA. SJB and DPN also contributed by recruitment and in the blood sample collection. All authors read and approved the final manuscript.

\section{Author details}

'School of Life Sciences, Pharmacy and Chemistry, Kingston University, Penrhyn Road, Kingston-upon-Thames, Surrey KT1 2EE, UK. ${ }^{2}$ Department of Chemistry, College of Science, United Arab Emirates University, Al Ain, UAE.

\section{Competing interests}

The authors declare that they have no competing interests.

Received: 6 May 2016 Accepted: 5 August 2016

Published online: 17 August 2016

\section{References}

1. Sallmann AR (1986) The history of diclofenac. Am J Med 80:29-33

2. Mazumdar K, Dutta NK, Dastidar SG, Motohashi N, Shirataki Y (2006) Diclofenac in the management of E. coli urinary tract infections. In Vivo 20:613-619

3. Dutta NK, Annadurai S, Mazumdar K, Dastidar SG, Kristiansen JE, Molnar J, Martins M, Amaral L (2007) Potential management of resistant microbial infections with a novel non-antibiotic: the anti-inflammatory drug diclofenac sodium. Int J Antimicrob Agents 30:242-249

4. Dastidar SG, Ganguly K, Chaudhuri K, Chakrabarty A (2000) The antibacterial action of diclofenac shown by inhibition of DNA synthesis. Int J Antimicrob Agents 14:249-251

5. Dorado P, Berecz R, Norberto M-J, Yasar Ü, Dahl ML, LLerena A (2003) CYP2C9 genotypes and diclofenac metabolism in Spanish healthy volunteers. Eur J Clin Pharmacol 59:221-225

6. Davies NM, Anderson KE (1997) Clinical pharmacokinetics of diclofenac. Clin Pharmacokinet 33:184-213

7. Kearney PM, Baigent C, Godwin J, Halls H, Emberson JR, Patrono C (2006) Do selective cyclo-oxygenase-2 inhibitors and traditional non-steroidal anti-inflammatory drugs increase the risk of atherothrombosis? Metaanalysis of randomised trials. Br Med J 332:1302-1308

8. Davies NM, Saleh JY, Skjodt NM (2000) Detection and prevention of NSAID-induced enteropathy. J Pharm Pharm Sci 3:137-155

9. Fortun PJ, Hawkey CJ (2005) Nonsteroidal antiinflammatory drugs and the small intestine. Curr Opin Gastroenterol 21:169-175

10. Kumar S, Samuel K, Subramanian R, Braun MP, Stearns RA, Chiu SHL, Evans DC, Baillie TA (2002) Extrapolation of diclofenac clearance from in vitro microsomal metabolism data: role of acyl glucuronidation and sequential oxidative metabolism of the acyl glucuronide. J Pharmacol Exp Ther 303:969-978

11. Tang W (2003) The metabolism of diclofenac-enzymology and toxicology perspectives. Curr Drug Metab 4:319-329

12. Boelsterli UA (2003) Diclofenac-induced liver injury: a paradigm of idiosyncratic drug toxicity. Toxicol Appl Pharmacol 192:307-322
13. Sachs UJ, Santoso S, Röder L, Smart E, Bein G, Kroll H (2004) Diclofenacinduced antibodies against red blood cells are heterogeneous and recognize different epitopes. Transfusion 44:1226-1230

14. den Braver-Sewradj SP, den Braver MW, Vermeulen NP, Commandeur JN, Richert L, Vos JC (2016) Inter-donor variability of phase I/phase II metabolism of three reference drugs in cryopreserved primary human hepatocytes in suspension and monolayer. Toxicol In Vitro 33:71-79

15. Hop CE, Cole MJ, Davidson RE, Duignan DB, Federico J, Janiszewski JS, Jenkins K, Krueger S, Lebowitz R, Liston TE (2008) High throughput ADME screening: practical considerations, impact on the portfolio and enabler of in silico ADME models. Curr Drug Metab 9:847-853

16. Madsen KG, Skonberg C, Jurva U, Cornett C, Hansen SH, Johansen TN, Olsen J (2008) Bioactivation of diclofenac in vitro and in vivo: correlation to electrochemical studies. Chem Res Toxicol 21:1107-1119

17. Chen C, Bujanover S, Kareht S, Rapoport AM (2015) Differential pharmacokinetics of diclofenac potassium for oral solution vs immediate-release tablets from a randomized trial: effect of fed and fasting conditions. Headache 55:265-275

18. Emami J, Ghassami N, Talari R (2007) A rapid and sensitive modified HPLC method for determination of diclofenac in human plasma and its application in pharmacokinetic studies. DARU 15:132-138

19. Kaphalia L, Kaphalia BS, Kumar S, Kanz MF, Treinen-Moslen M (2006) Efficient high performance liquid chromatograph/ultraviolet method for determination of diclofenac and 4'-hydroxydiclofenac in rat serum. J Chromatogr B 830:231-237

20. Yilmaz B, Asci A, Palabiyik SS (2011) HPLC method for determination of diclofenac in human plasma and its application to a pharmacokinetic study in Turkey. J Chromatogr Sci 49:422-427

21. El-Sayed YM, Abdel-Hameed ME, Suleiman MS, Najib NM (1988) A rapid and sensitive high-performance liquid chromatographic method for the determination of diclofenac sodium in serum and its use in pharmacokinetic studies. J Pharm Pharmacol 40:727-729

22. Zecca $L$, Ferrario P, Costi $P$ (1991) Determination of diclofenac and its metabolites in plasma and cerebrospinal fluid by high-performance liquid chromatography with electrochemical detection. J Chromatogr B Biomed Sci Appl 567:425-432

23. Gimenes DT, Cunha RR, de Carvalho Ribeiro MM, Pereira PF, Muñoz RA, Richter EM (2013) Two new electrochemical methods for fast and simultaneous determination of codeine and diclofenac. Talanta 116:1026-1032

24. Liu SC, Tsai TH (2002) Determination of diclofenac in rat bile and its interaction with cyclosporin A using on-line microdialysis coupled to liquid chromatography. J Chromatogr B 769:351-356

25. Fotouhi L, Seidi S, Yamini Y, Hosseini E (2015) Evaluation of pulsed electromembrane extraction for the analysis of diclofenac and mefenamic acid in biological fluids. Anal Methods 7:2848-2854

26. Abdel-Hamid ME, Novotny L, Hamza H (2001) Determination of diclofenac sodium, flufenamic acid, indomethacin and ketoprofen by LC-APCI-MS. J Pharm Biomed Anal 24:587-594

27. Agüera A, Pérez Estrada L, Ferrer I, Thurman E, Malato S, Fernández-lba A (2005) Application of time-of-flight mass spectrometry to the analysis of phototransformation products of diclofenac in water under natural sunlight. J Mass Spectrom 40:908-915

28. Sebő́k Á, Vasanits-Zsigrai A, Palkó G, Záray G, Molnár-Perl I (2008) Identification and quantification of ibuprofen, naproxen, ketoprofen and diclofenac present in waste-waters, as their trimethylsilyl derivatives, by gas chromatography mass spectrometry. Talanta 76:642-650

29. Kadowaki H, Shiino M, Uemura I, Kobayashi K (1984) Sensitive method for the determination of diclofenac in human plasma by gas chromatography-mass spectrometry. J Chromatogr B Biomed Sci Appl 308:329-333

30. Borenstein MR, Xue Y, Cooper S, Tzeng T-B (1996) Sensitive capillary gas chromatographic-mass spectrometric-selected-ion monitoring method for the determination of diclofenac concentrations in human plasma. J Chromatogr B Biomed Sci Appl 685:59-66

31. Yilmaz B (2010) GC-MS determination of diclofenac in human plasma. Chromatographia 71:549-551

32. Choi MH, Choi YK, Chung BC (1999) Rapid and sensitive analysis of diclofenac in human plasma by GC/SIM/MS. Anal Lett 32:2245-2253 
33. Sahoo NK, Sahu M, Rao PS, Ghosh G (2015) Solid phase extraction and quantification of diclofenac sodium in human plasma by liquid chromatography-tandem mass spectrometry. J Anal Chem 70:424-430

34. Food and Drug Administration (2001) Guidance for industry: bioanalytical method validation. US Department of Health and Human Services; Food and Drug Administration, Center for Drug Evaluation and Research (CDER), Mexico
35. World Medical Association (2001) World Medical Association Declaration of Helsinki. Ethical principles for medical research involving human subjects. Bull WHO 79:373

36. Willis J, Kendall M, Flinn R, Thornhill D, Welling P (1979) The pharmacokinetics of diclofenac sodium following intravenous and oral administration. Eur J Clin Pharmacol 16:405-410

\section{Submit your manuscript to a SpringerOpen ${ }^{\circ}$ journal and benefit from:}

- Convenient online submission

\section{- Rigorous peer review}

Immediate publication on acceptance

- Open access: articles freely available online

- High visibility within the field

- Retaining the copyright to your article 